\title{
Argentina y la autonomía en la globalización financiera: La naturaleza de su respaldo durante el proceso de reestructuración de su deuda externa (2002-2005)*
}

\section{Argentina and Autonomy in Financial Globalization: The Nature of its Support during the Process of Foreign Debt Restructuring (2002-2005)}

Nicolás Creus ${ }^{* *}$

Recibido: 18/05/2015

Aprobado: 14/07/2015

Disponible en línea: 30/11/2015

\section{Resumen}

El presente artículo se propone analizar la autonomía lograda por Argentina durante el proceso de reestructuración de su deuda externa entre 2002 y 2005. El hecho de que un Estado con sus características haya logrado preservar espacios de decisión propia en un tema tan complejo en el campo de las finanzas internacionales, constituye un acontecimiento novedoso y anómalo que merece ser estudiado. En tal sentido, resulta fundamental desentrañar las particularidades de la autonomía alcanzada para poder determinar si se trató de una construcción genuina y por tanto sostenible en el tiempo, o si por el contrario fue

\begin{abstract}
This article analyses the autonomy achieved by Argentina during the process of foreign debt restructuring, between 2002 and 2005. The fact that a state with its features has managed to preserve spaces for its own decisions in such a complex topic in the field of international finance represents a novel and anomalous event that deserves to be studied. In this regard, it is essential to unravel the details of the achieved autonomy in order to be able to determine if it was a genuine construction and therefore sustainable over time, or if instead it was rather a product of a particular context. To answer this
\end{abstract}

doi:10.11144/Javeriana.papo20-2.augf

${ }^{*}$ Artículo de reflexión.

** Docente de Política Internacional Argentina, Facultad de Ciencia Política y Relaciones Internacionales de la Universidad Nacional de Rosario (UNR), Argentina. Licenciado en Relaciones Internacionales (UNR). Doctorando en Relaciones Internacionales (UNR). Becario de postgrado del Consejo Nacional de Investigaciones Científicas y Técnicas (CONICET). Correo electrónico: nicolascreus@gmail.com 


\section{Nicolás Creus}

más bien el producto de un contexto particular. question, it is necessary to analyze the nature of Para responder a tal interrogante, es preciso analizar la naturaleza del respaldo con el que contó the support of such autonomy because it is there dicha autonomía, en tanto que es allí donde reside la clave de su sustentabilidad.

\section{Palabras clave}

Argentina; autonomía; globalización financiera; reestructuración de deuda; Estados Unidos

\section{Cómo citar este artículo:}

Creus, N. (2015). Argentina y la autonomía en la globalización financiera. La naturaleza de su respaldo durante el proceso de reestructuración de su deuda externa (2002-2005). Papel Político, 20(2), 547-563. http://dx.doi. org/10.11144/Javeriana.papo20-2.augf

\section{Keywords}

Argentina; autonomy; financial globalization; debt restructuring; United States 


\section{Introducción}

En un contexto de fuerte globalización financiera como el que caracteriza a las relaciones internacionales en las últimas décadas, la forma en la cual un Estado articula su vínculo con el sistema financiero internacional resulta clave y determinante para definir su modelo de inserción en el mundo y valorar sus posibilidades de actuación autónoma. Argentina constituye un claro ejemplo en este sentido, en tanto que desde su temprana inserción en la globalización financiera a finales de los años setenta, su vulnerabilidad externa se agudizó considerablemente. El país padeció la imposición de condicionamientos constantes por parte de diferentes actores de la comunidad financiera internacional -tanto estatales como no estatales-, los cuales constriñeron de manera significativa su capacidad para tomar decisiones y generar iniciativas propias.

Esta experiencia histórica parece confirmar aquellas hipótesis que destacan el debilitamiento del Estado y la erosión de la autonomía nacional frente a la profundización del proceso globalizador. Desde esta perspectiva, se entiende que los mercados globales limitan el margen de maniobra de los Estados y castigan aquellas conductas que no se ajustan a sus parámetros y expectativas, restringiendo así los espacios para la implementación de políticas heterodoxas.

En línea con estos argumentos, los Estados periféricos y en desarrollo -como es el caso de Argentina- no se encuentran en condiciones de sostener criterios propios frente a los diferentes actores que componen el sistema financiero internacional. Este panorama se agrava aún más en situaciones de alto endeudamiento y desequilibrios macroeconómicos importantes. En tal contexto, las posibilidades de preservar autonomía son mínimas, en el mejor de los casos.

No obstante, Argentina mediante el manejo de la crisis de su deuda soberana luego del default declarado sobre una parte importante de la misma en diciembre de 2001, puso de manifiesto el carácter exagerado -o al menos relativo- de las referidas apreciaciones. En oposición a lo que muchos esperaban, el país logró preservar cierta autonomía y obtener resultados deseados en las negociaciones que llevó adelante con los diferentes actores que intervinieron -de manera directa o indirecta- en el proceso que condujo a la exitosa reestructuración de su deuda con los acreedores privados, concretada mediante el canje de 2005 .

El hecho de que un Estado con las características de Argentina haya logrado preservar espacios de decisión propia en un tema tan complejo en el campo de las finanzas internacionales, constituye un acontecimiento novedoso y anómalo que merece ser estudiado. En tal sentido, resulta fundamental desentrañar las particularidades de la autonomía alcanzada para poder determinar si se trató de una construcción genuina y por tanto sostenible en el tiempo, o si por el contrario fue más bien el producto de un contexto particular, quedando así restringida a una coyuntura específica y delimitada. 
El presente artículo sostiene que para responder a tal interrogante, es preciso analizar la naturaleza del respaldo con el que contó dicha autonomía, en tanto que es allí donde reside la clave de su sustentabilidad.

\section{Entre la debilidad y la autonomía}

En términos generales, los trabajos que se han ocupado de estudiar las causas y los orígenes de la crisis de 2001 en Argentina pueden dividirse en dos grandes grupos, tomando como criterio el planteo de Rodrik (2003) cuando se pregunta acerca de si Argentina representa un caso de globalización que ha ido demasiado lejos o más bien no lo suficiente. En respuesta a tal interrogante, el autor cuestiona que:

Muchos llegarán a la conclusión de que Argentina tomó la ruta incorrecta, no porque haya ido demasiado lejos en la búsqueda del Santo Grial de la globalización, sino más bien y por el contrario, porque no fue lo suficientemente lejos. La solución desde esta perspectiva radica en mejorar el modelo de Argentina, minando la soberanía nacional y reduciendo aún más la capacidad de respuesta de la gestión económica de las fuerzas políticas domésticas. Lo que necesitan los gobiernos nacionales son mecanismos de compromiso más fuertes. (Rodrik, 2003, p. 19)

Subyace que quienes se decantan por esta opción, entienden la globalización como un proceso neutro, sin riesgos e igualmente beneficioso para todos. En tal sentido, en línea con este razonamiento existe una única forma de insertase de manera exitosa: cediendo espacios de decisión a favor de la idea de los mercados auto-regulados. Ir en contra de esta premisa básica conduce indefectiblemente al fracaso y a la marginación internacional.

En contraposición con esta interpretación, Eatwell y Taylor (2006, p. 10) en un análisis crítico sobre el funcionamiento de las finanzas globales, sostienen que los mercados solo son eficientes si están eficientemente regulados. Mucho más cerca de este segundo enfoque -aunque sin entrar en la discusión normativa sobre la arquitectura del sistema financiero internacional-, el presente trabajo entiende las relaciones internacionales como relaciones de poder. El proceso de globalización no escapa a esta lógica, de modo que no puede ser entendido como un proceso neutro. Este es más bien un producto resultante de las referidas relaciones de poder, de las cuales participan tanto actores estatales como no estatales. Desde esta perspectiva, la autonomía entendida como "la máxima capacidad de decisión propia que se puede tener, teniendo en cuenta los condicionamientos objetivos del mundo real" (Puig, 1980, p. 149), constituye un activo fundamental a la hora de definir el modelo de desarrollo y de inserción internacional de un país.

El propio Rodrik (2003, p. 20) advierte que: "la evidencia histórica muestra que la solución para el subdesarrollo no radica en la adopción de modelos institucionales 
extranjeros o en el debilitamiento de la autonomía nacional. Radica en el aumento de la capacidad del Estado". En línea similar, otros autores explican el fracaso de Argentina a partir del modo en el cual se insertó a la globalización financiera y sugieren que el país no debería someterse a las condiciones y lineamientos del Fondo Monetario Internacional (FMI). Por el contrario, proponen la implementación de políticas heterodoxas para corregir los desequilibrios (Cibils, Weisbrot, \& Kar, 2002; Stiglitz, 2002).

En términos generales, esta fue la opción política que pretendió seguir Argentina para resolver la crisis de su deuda y recomponer sus vínculos con el sistema financiero internacional. Sin embargo, más allá de la importancia y de lo valioso de definir un curso de acción de este tipo, resulta imperioso reflexionar sobre la capacidad de un Estado como Argentina para sostener tales políticas, en un contexto de fuerte debilidad, con urgencias financieras y acosada por sus acreedores. A la luz de la experiencia histórica, resulta evidente que la autonomía -sobre todo en la globalización financiera- no puede ser tan solo una cuestión de voluntarismo, ni mucho menos el resultado de la mera declamación. La decisión política es una condición subjetiva necesaria pero no suficiente, es menester también la concurrencia de condiciones objetivas que le den sustento y respaldo a la vocación autonomista.

A lo largo del proceso en cuestión, Argentina firmó dos acuerdos stand by con el FMI -uno transitorio en enero de 2003 y el otro de mediano plazo en septiembre del mismo año-, consiguiendo así evitar la extensión del default con los organismos multilaterales sin comprometer sus alicaídas reservas (Ferrer, 2003a; 2003b) y logrando en ambos sostener sus criterios por sobre los de su contraparte negociadora, sobre todo en las cuestiones más espinosas, tales como la determinación del superávit fiscal, la revisión y renegociación de los contratos con las empresas privatizadas proveedoras de servicios públicos y la definición de los principios que debían orientar las negociaciones con los acreedores privados. Esto además, lo confirmó en las sucesivas revisiones correspondientes a cada uno de los acuerdos.

En lo que respecta al primer ítem, Argentina se comprometió a asegurar un superávit primario consolidado del $2,5 \%$ del PBI en el acuerdo de enero (2,1\% correspondiente a la nación y $0,4 \%$ correspondiente a las provincias) y del $3 \%$ en el acuerdo de septiembre $(2,4 \%$ para la nación y 0,6\% para las provincias), mientras que las pretensiones del FMI eran bastante más elevadas, rondando entre $4 \%$ y $5 \%$. En cuanto al segundo tema referenciado, el gobierno argentino evitó asumir compromisos concretos respecto a la subida de tarifas reclamada por las privatizadas, cuando el FMI -en línea con el pedido de las empresaspretendía aumentos que oscilaban entre 20\% y 30\% (Ferrer, 2003a; 2003b; Bembi \& Nemiña, 2007; Lavagna, 2011). Por último, en lo relativo al tercer punto, Argentina neutralizó las intenciones del FMI dirigidas a condicionar la negociación con los privados, logrando mantener separados ambos procesos negociadores (Cooper \& Momani, 2005). 
Finalmente, Argentina llevó a cabo con los acreedores privados una reestructuración de deuda con características ciertamente excepcionales, en tanto que la misma -además de mantener al FMI al margen- contempló una fuerte quita sobre el valor nominal del capital (alrededor de 75\%), una reducción en las tasas de interés reconocidas y una extensión considerable en los plazos de maduración de los nuevos bonos (Damill, Frenkel, \& Rapetti, 2005; Sturzenegger \& Zettelmeyer, 2006; Fernández, 2006). El canje se concretó en junio de 2005, reportando una aceptación del 76,15\%. La operatoria se ajustó a los parámetros deslizados en la denominada 'propuesta de Buenos Aires', presentada en junio de 2004, la cual si bien implicó mejoras importantes con respecto a la anterior 'propuesta de Dubai' formulada en septiembre de 2003, en términos generales reflejó los objetivos e intereses de Argentina ${ }^{1}$.

Ahora bien, ¿cómo pudo un Estado periférico y en desarrollo como Argentina lograr esto desde la debilidad en la que se encontraba? En otras palabras, ¿̇dónde estuvo el respaldo de la autonomía que ostentó el país? En este punto, desde diferentes perspectivas y con mayor o menor énfasis, muchos trabajos coinciden en destacar el rol de Estados Unidos como un factor crucial que jugó a favor de los intereses de Argentina, apuntalando y reforzando sus posiciones en momentos claves durante las negociaciones (Damill et al., 2005; Helleiner, 2005; Busso, 2006; Bembi \& Nemiña, 2007; Lavagna, 2011).

Asumiendo este supuesto de partida y en función del objetivo planteado en la introducción, lo fundamental desde la perspectiva del presente trabajo radica en dilucidar por qué Estados Unidos asumió una postura funcional e incluso por momentos abiertamente favorable a los intereses de Argentina. Despejar este interrogante es clave para poder valorar las características de la autonomía alcanzada.

\section{El apoyo de Estados Unidos: ¿condición estructural o dato circunstancial?}

Durante la década del noventa, Argentina sustentó su inserción internacional sobre la base de la configuración de una 'relación especial' con Estados Unidos. El académico Carlos Escudé (1992, p. 45), planteó en aquel entonces que la política exterior de un Estado periférico y de escasa relevancia estratégica para los intereses vitales de la principal potencia mundial -como es el caso de Argentina- debe tener:

\footnotetext{
${ }^{1}$ Las mejoras más significativas radicaron en el hecho de que si bien se preservó la quita en términos nominales, la 'propuesta de Buenos Aires' contempló intereses no pagados y devengados hasta la declaración del default no incluidos en la 'propuesta de Dubai', al tiempo que estableció que los tres tipos de bonos que conformaban la oferta (Par, Cuasi-par y Discount) se emitirían con fecha 31 de diciembre de 2003, momento a partir del cual comenzarían a devengar intereses, garantizando así pagos inmediatos al concluir el canje. Además, entre otros aspectos, se brindaron las precisiones y los detalles técnicos sobre cómo se aplicaría el pago extra que recibirían los acreedores a partir del cupón ligado al PBI que incluía la oferta.
} 
[...] el perfil más bajo posible en todos aquellos temas en que la política del país se contrapone con la de las potencias dominantes, y debe adaptar sus objetivos políticos a los de la potencia dominante en su región, a menos que dicha adaptación tenga costos materiales tangibles.

El autor proponía así, llevar adelante una estrategia de alineamiento con el hegemón, la cual conduciría primariamente a la reducción de los costos y riesgos derivados de la implementación de políticas confrontacionistas ${ }^{2}$. Asimismo, otros veían incluso en esta política la posibilidad de 'reincorporar Argentina al primer mundo', en tanto que el alineamiento, además de reducir costos y riesgos, permitiría obtener el apoyo de Estados Unidos en diferentes temas de interés significativos para el país (De la Balze, 1998).

En el contexto de estas ideas, el gobierno argentino procuró reforzar su nivel de coincidencias con Estados Unidos. En tal sentido, adhirió a las recetas del denominado Consenso de Washington dando curso a un fuerte proceso de liberalización comercial, apertura financiera y desregulación del mercado de capitales. De este modo, desde la perspectiva de Estados Unidos, Argentina adquirió cierto valor político, en tanto que se convirtió en un modelo paradigmático de las reformas económicas impulsadas por parte de la potencia para la región y fue catalogada como un ejemplo por los mercados financieros internacionales.

Esta particularidad permite entender y explicar entre otras cosas, el apoyo y la complicidad del FMI con las políticas implementadas por Argentina en aquellos años, aún cuando los fundamentos macroeconómicos comenzaban a mostrar inconsistencias y daban señales de fragilidad. Michael Mussa, ex consultor económico y director del departamento de investigación del organismo entre 1991 y 2001, destaca que: "Con el colapso de muchas de las economías del milagro asiático en 1997-1998 y las crecientes dificultades en Brasil y Rusia, la Argentina se destacaba como una clara historia de éxito", esto era de suma importancia desde el punto de vista del autor, en tanto que le permitía al FMI -en un contexto de críticas generalizadas por su rol en la crisis de Asia-, "señalar al menos un país importante en el cual los programas del Fondo parecían estar respaldando políticas económicas exitosas” (Mussa, 2002, p. 30).

Sin embargo, la relevancia política adquirida por el país se esfumó cuando los problemas económicos se tornaron imposibles de resolver y el default se presentó como una alternativa inevitable. En tales condiciones, Argentina ya no era un actor funcional para la estrategia internacional de Estados Unidos, de modo que la 'relación especial' configurada durante los años noventa había perdido su razón de ser desde la perspectiva de los objetivos de la potencia. La decisión política fue dejar caer a Argentina. Más

\footnotetext{
2 Según Escudé (1992, p. 112), este debe ser el principal objetivo de la dimensión política de la política exterior de un Estado dependiente.
} 
aún, una vez producido el default, rescatar al país tampoco era conveniente, ya que tal acto implicaría asumir culpas y responsabilidades en la debacle, evidenciando el fracaso del modelo implementado. En tal sentido, resulta evidente que la postura funcional y de apoyo que luego asumió Estados Unidos para con Argentina, fundamentalmente a partir de mediados de 2002, no puede ser explicada como consecuencia -ni como resabio- de la 'relación especial' entre ambos actores, ya que para entonces se había terminado desde todo punto de vista.

Del mismo modo, aunque para muchos resulte atractivo y tentador, tampoco parece posible explicar la actitud de Estados Unidos a partir de valoraciones en torno a la relevancia de Argentina como actor internacional. Algunos analistas como Helleiner (2005, p. 959) sostienen que uno de los factores que impulsó el accionar de Estados Unidos fue la necesidad y el deseo de contar con el apoyo político de Argentina en un contexto regional cambiante, asignándole cierta importancia estratégica en el marco de la política hemisférica. Según este autor, Argentina era una pieza importante para la concreción del área de libre comercio para las Américas (ALCA). Sin embargo, esto no parece ser un motivo suficiente para explicar el apoyo, considerando que aún bajo gobiernos que se caracterizaron por la implementación de políticas económicas ortodoxas, tal como lo fueron los gobiernos de Carlos Menem (1989-1999) y de Fernando De la Rúa (1999-2001), Argentina no convalidó su ingreso al ALCA en los términos pretendidos por Estados Unidos, manteniéndose en esta cuestión en sintonía con Brasil, su principal socio comercial. De este modo, no había indicios de que tal postura se pudiera llegar a modificar.

Además, la capacidad del país para gravitar en la región se había devaluado considerablemente vis a vis el ascenso de Brasil, cada vez más afirmado -por peso específico y atributos materiales- en su condición de potencia regional y referente de la estabilidad en América del Sur. Del mismo modo, cabe destacar que la economía argentina representa una porción muy pequeña de la economía global, mientras que su participación en los flujos de comercio mundial también es limitada -en ambos casos su contribución se ubica alrededor del o,4\%-. La diferencia con Brasil en estos puntos es clara. En tal sentido, es este -y no Argentina- el actor clave para Estados Unidos en la región. Por último, en términos geopolíticos, Argentina no se encuentra ubicada en una zona de las denominadas como 'sensibles' para los intereses vitales de la potencia, lo cual en tal caso podría haber servido como justificativo para un tratamiento diferenciado. La condición de aliado extra OTAN tampoco gravitó en este sentido.

De esta manera, descartadas las diversas opciones barajadas hasta aquí, resulta evidente que la posición funcional y de apoyo asumida por Estados Unidos desde la segunda mitad de 2002 hasta el canje de deuda concretado en 2005, no puede entenderse como una condición estructural. Por el contrario, en el presente trabajo se sostiene que la postura norteamericana respondió más bien a consideraciones estratégicas de orden 
sistémico - vinculadas a la resolución de la crisis argentina- que circunstancialmente resultaron funcionales a los objetivos del país sudamericano. Tales consideraciones tuvieron que ver con dos cuestiones estrechamente relacionadas, propias de la política financiera internacional de Estados Unidos, a saber: la puesta en práctica de un nuevo enfoque para la resolución de las crisis de deuda soberana y la contención de un eventual efecto de contagio que pudiera derivar en dificultades para la economía global. Esta particularidad le brindó a Argentina una autonomía engañosa y endeble, circunscripta a la coyuntura y difícil de sostener en los mismos términos en el futuro.

Con el objeto de corroborar las afirmaciones planteadas, en el próximo apartado se procede a un análisis detallado de las consideraciones estratégicas que explican el comportamiento de Estados Unidos y revelan el carácter transitorio de su posición consonante con los intereses de Argentina, poniendo de manifiesto la fragilidad de la autonomía alcanzada.

\section{Los intereses estratégicos de Estados Unidos y las coincidencias transitorias con Argentina}

Teniendo en cuenta la inexistencia de mecanismos supranacionales efectivos, resulta evidente que el modo de resolver las crisis de deuda soberana depende de las relaciones de poder que se configuran entre el país deudor y sus acreedores. Dadas las implicancias que este tipo de procesos pueden tener sobre la estabilidad y el normal funcionamiento del sistema financiero internacional, un factor clave que condiciona fuertemente la configuración de dichas relaciones -además de los recursos que poseen cada una de las partes- tiene que ver con el rol de Estados Unidos, en tanto principal potencia y garante del orden sistémico.

Tal como lo advierte Helleiner (2005), en las crisis de deuda que tuvieron lugar durante las décadas del ochenta y del noventa, Estados Unidos facilitó soluciones favorables a los intereses de los acreedores. Esto lo hizo mediante la organización y coordinación de paquetes de asistencia financiera, tendientes a contener las crisis y rescatar a los inversores privados, asegurando el cobro de sus acreencias. Tal asistencia estuvo condicionada a la adopción por parte de los países deudores de duros programas de ajuste estructural, patrocinados y monitoreados por el FMI. Se buscaba recomponer la capacidad de pago de los deudores en el corto plazo mediante una combinación de ajuste y financiamiento fresco. En este sentido, Estados Unidos promovió un rol activo para las instituciones financieras internacionales, fundamentalmente para el FMI, que durante estos años comenzó a oficiar como prestamista de última instancia.

Hacia finales de los noventa, las sucesivas crisis financieras y los enormes paquetes de rescate que fueron necesarios para paliarlas, comenzaron a generar críticas cada vez 
mayores hacia este enfoque. Los cuestionamientos giraron principalmente en torno a la idea de que las políticas de rescate distorsionaban el funcionamiento normal y eficiente de los mercados, en tanto que alentaban conductas irresponsables por parte de acreedores y deudores, los cuales al tener certeza de que eventualmente serían rescatados, no consideraban adecuadamente los riesgos inherentes a sus acciones. Esto se conoció en la literatura especializada como riesgo moral $^{3}$.

En consecuencia, para superar estos problemas se planteó la necesidad de un cambio de enfoque, en donde el mercado sea el encargado de distribuir los costos derivados de las malas decisiones financieras. Estas ideas ganaron espacio en el congreso norteamericano y se cristalizaron en el informe de la Comisión Meltzer, publicado en marzo de 2000, que recomendaba limitar y reducir, tanto las políticas de rescate como la actividad del FMI. Con la llegada de la administración Bush en 2001, se consolidó y reforzó este cambio de política tendiente a romper con el intervencionismo que había caracterizado a la administración Clinton. El nuevo enfoque de Estados Unidos sería uno de prescindencia y laissez faire. No habría más rescates, de ahora en adelante los inversores internacionales debían ser más precavidos en sus negocios.

La crisis argentina brindó la oportunidad perfecta para poner en práctica la nueva política. En un principio, esta no fue favorable para los intereses de Argentina, ya que las autoridades del gobierno nacional demandaban una ayuda financiera de entre 20.000 y 25.00o millones de dólares para contener la crisis y estabilizar la situación. El problema -tal como se mencionó-, radicaba en el hecho de que el mundo había cambiado y Estados Unidos ya no estaba dispuesto a prestar dicha asistencia, el país debía negociar sin ayuda con sus acreedores.

Además, los años 2002 y 2003 estaban cargados de vencimientos importantes con los organismos multilaterales, con los cuales se quería evitar la extensión del default. La situación financiera era sumamente frágil y el FMI utilizó esto como un instrumento de presión, ligando la firma de un acuerdo que permitiera refinanciar esos vencimientos con la implementación de condicionalidades tendientes a direccionar la mayor cantidad de recursos posibles al pago de los servicios de la deuda. El Fondo necesitaba resguardar su cuestionada credibilidad frente a la comunidad financiera internacional, de modo que procuró dar prioridad a la defensa de los intereses de los acreedores, intentando asegurar el mayor cobro de acreencias posible, aun a costa del crecimiento del país deudor.

\footnotetext{
${ }^{3}$ Las discusiones en torno a este concepto emergieron con fuerza en el contexto de sucesión de crisis financieras descripto y ganaron espacio en los debates sobre la arquitectura financiera internacional, el rol del FMI en esos años y la necesidad de un mayor involucramiento del sector privado en la resolución de los problemas (Lane \& Phillips, 2000).
} 
La inviabilidad doméstica para la implementación de las exigencias del Fondo, así como también las restricciones internacionales para conseguir financiamiento nuevo, condujeron a la renuncia del ministro de Economía, Jorge Remes Lenicov y a su reemplazo con Roberto Lavagna. En este complejo escenario, Argentina obtuvo algo de aire a partir de la incipiente recomposición de sus recursos propios. La brusca modificación de los precios relativos provocada por la devaluación permitió recobrar la competitividad de los bienes comercializables internacionalmente. Los bienes importados se encarecieron, al tiempo que los exportables se abarataron en el plano internacional, contribuyendo así a la corrección del desequilibrio externo. La cuenta corriente de la balanza de pagos pasó a ser superavitaria luego de varios años de arrojar déficit (Ferrer, 2003a; 2003b; Damill \& Frenkel, 2013).

Además, el fuerte aumento en el precio de las commodities contribuyó a engrosar aún más el superávit de la cuenta corriente y consecuentemente a recomponer las alicaídas reservas internacionales. Estas últimas, ingresaron en una senda de fuerte crecimiento a partir del tercer trimestre de 2002, duplicándose en tan solo dos años. Pasaron de 9.000 millones de dólares a 18.000 millones en el tercer trimestre de 2004. Esta tendencia ascendente continuó en los años subsiguientes.

El ministro Lavagna -en consonancia con el clima internacional del momento y considerando las condiciones referidas-desistió de solicitar 'fondos frescos' tal como lo había sugerido su antecesor en el Ministerio de Economía, Remes Lenicov. Este cambio en la estrategia negociadora fue trascendental y marcó un quiebre en el proceso, ya que le permitió a Argentina sintonizar con la nueva política financiera internacional de Estados Unidos, posibilitando así la emergencia -aunque sea transitoria- de intereses coincidentes entre ambos actores. El propio Lavagna (2011) relata que durante una reunión que mantuvo a fines de junio de 2002 en Washington con el secretario del Tesoro de Estados Unidos Paul O’Neill, este se sorprendió cuando le manifestó que Argentina no buscaba 'fondos frescos', sino tan solo el roll over o reprogramación. “¿No quieren plata fresca? Eso facilita las cosas", le habría respondido el funcionario, casi sin entender por qué entonces no avanzaban las negociaciones. Claramente, los cuadros técnicos del Fondo le habían estado ocultando información al gobierno de Estados Unidos para mantener su presión sobre Argentina.

De este modo, Argentina logró al menos tres cosas importantes: 1. Exponer al FMI como el principal responsable de las demoras en la concreción de los acuerdos, ya que no parecían existir mayores motivos que justificaran su postura intransigente, al menos desde la perspectiva del nuevo enfoque impulsado por el gobierno de Estados Unidos para la resolución de las crisis de deuda soberana. Esto debilitó institucionalmente aún más al organismo, que ya no contaba con el apoyo político de su principal contribuyente, con todo lo que esto representa; 2. Reforzar su posición para imponer un quite sobre la deuda con los acreedores privados, entendiendo que ante la ausencia de rescate y sin 
asistencia financiera, ellos también se convertían en parte del problema y debían compartir los costos de la reestructuración; y 3. Aumentar los márgenes para la adopción de posiciones más firmes y osadas, tales como rechazar el uso de reservas para cancelar obligaciones con los organismos multilaterales hasta tanto no tener certezas suficientes de que tales pagos fueran a ser compensados de inmediato.

En línea con este último principio, en noviembre de 2002 el gobierno argentino incumplió un vencimiento con el Banco Mundial por 805 millones de dólares ${ }^{4}$ y en enero de 2003 hizo lo propio frente a un vencimiento con el BID por 680 millones de dólares. De manera similar, en septiembre de 2003 -en el marco de las negociaciones por la firma del stand by de mediano plazo-, amenazó con la posibilidad de entrar en default con el propio FMI, al plantear la imposibilidad de cancelar un vencimiento por casi 3.000 millones de dólares, sin la garantía de la firma del acuerdo que permitiera la compensación de tales fondos. La amenaza se repitió en marzo de 2004 ante un vencimiento de 3.200 millones de dólares, en el contexto de las negociaciones para la aprobación de la segunda revisión correspondiente al acuerdo de septiembre de 2003 (Cooper \& Momani, 2005; Bembi \& Nemiña, 2007).

El éxito de la nueva política financiera internacional de Estados Unidos estaba íntimamente ligado a la contención del contagio. Si este ocurría, el fracaso sería total. De hecho, muchos analistas se mostraban escépticos con respecto a la suerte del nuevo enfoque y pensaban que no se podría sostener. Por esta razón, la dilación constante y el empantanamiento frecuente en el cual caían las negociaciones entre Argentina y el FMI, no representaban buenas señales para la política norteamericana, producto de la incertidumbre que se generaba en torno a la estabilidad de la economía global. Cabe recordar que el FMI tenía una elevada exposición crediticia en los mercados emergentes, lo cual aumentaba los riesgos asociados a un eventual contagio ${ }^{5}$.

Los temores comenzaron a agudizarse y se tornaron ciertamente tangibles a partir de junio de 2002, cuando el riesgo país de Brasil medido por Morgan registró un nuevo salto -de aproximadamente un poco más del 50\%, en relación al promedio registrado en mayo- que lo llevó a superar los 1.500 puntos básicos, para seguir por la senda ascendente en los meses subsiguientes, alcanzando picos por encima de los 2.000 puntos durante los meses de septiembre y octubre. El índice Bovespa registró pérdidas de alrededor de 30\% entre los meses de mayo y octubre de 2002. La amenaza de contagio

\footnotetext{
${ }^{4} \mathrm{~A}$ fines de no caer en una confrontación a ultranza con la comunidad financiera internacional, Argentina incumplió el pago del monto correspondiente al capital de la deuda -725 millones de dólares-, pero abonó puntualmente los intereses.

${ }^{5}$ En 2003 85\% de los préstamos del fondo estaban concentrados en cinco países: Brasil, Turquía, Argentina, Indonesia y Rusia, en ese orden. Argentina por sí sola representaba alrededor de $16 \%$ del total de acreencias del organismo (Bembi \& Nemiña, 2007).
} 
a Brasil tuvo un gran efecto amplificador en la región. El riesgo país se disparó fuerte en Uruguay, pasando de 900 puntos a finales de mayo a 3.00o para finales de julio, en tanto que las bolsas de México y Chile también sufrieron caídas importantes. Esta situación amenazaba uno de los postulados básicos enunciados por el subsecretario del Tesoro, John Taylor, acerca de que el contagio no era automático y que las economías con finanzas ordenadas permanecerían inmunes (Taylor, 2004).

Tales condiciones hicieron converger aún más los intereses de Argentina y Estados Unidos y determinaron la decisión de este último de abandonar la prescindencia entendida en un sentido estricto, para pasar a presionar al FMI en pos de que flexibilizara sus posturas cada vez que las negociaciones caían en un 'punto muerto'. De este modo, Estados Unidos le brindó a Argentina un respaldo político -no financiero- fundamental, que le permitió al país preservar autonomía frente a sus diversos acreedores y reestructurar su deuda en condiciones sostenibles y al mismo tiempo, compatibles con su recuperación económica. Este respaldo se expresó, no solo mediante declaraciones públicas oficiales favorables de parte de funcionarios de primera línea del gobierno norteamericano e incluso del propio presidente Bush, sino y sobre todo a través del apoyo concreto brindado por la potencia en el seno del directorio ejecutivo del Fondo cada vez que se discutía y se tomaban decisiones sobre el caso argentino.

No obstante, las coincidencias eran claramente transitorias. El respaldo de Estados Unidos no implicaba necesariamente un aval para la implementación en cualquier contexto de políticas económicas y financieras heterodoxas. Por el contrario y como advierte Helleiner (2005), el nuevo enfoque constituyó un claro reflejo de la ideología neoliberal, partidaria de no intervenir otorgando nuevos fondos y de dejar actuar al mercado sin introducir distorsiones que pudieran alterar su natural funcionamiento.

El apoyo norteamericano bajó su intensidad cuando las exigencias del FMI no constituyeron una asfixia tal para Argentina que pudiera poner en riesgo el proceso de reestructuración de la deuda y amenazar la estabilidad del sistema. Esto ocurrió por ejemplo en el marco de las negociaciones por la tercera revisión correspondiente al acuerdo de septiembre de 2003, llevadas a cabo luego de la presentación de la 'propuesta de Buenos Aires' en junio de 2004. En esta ocasión, Argentina enfrentó renovadas presiones por parte del FMI para asegurar un superávit fiscal más elevado para el año 2005 y en consecuencia, introducir nuevas mejoras en la oferta para los acreedores privados. A diferencia de lo ocurrido en momentos anteriores, Estados Unidos adoptó una posición equidistante entre las partes. Como destacan Bembi y Nemiña (2007, p. 84), mientras advirtió por un lado que el FMI no debía intervenir en la negociación entre Argentina y los privados -ya que se trataba de un asunto bilateral- por el otro y en lo relativo al superávit, señaló que Argentina se había comprometido a garantizar una meta superior al 3\% para el 2005. 
Para este momento y como se mencionó anteriormente, las reservas de Argentina se habían duplicado y las expectativas sobre la economía habían mejorado sustancialmente. En tal sentido, se entendía que el país estaba en condiciones de asegurar un superávit mayor o de lo contrario, prescindir de los desembolsos del FMI. La posición del FMI, menos expuesta a las presiones de Estados Unidos, se mantuvo inalterable. Argentina optó por rechazar las exigencias y solicitar la suspensión del acuerdo en agosto de 2004. Esto implicaba, como señalan Bembi y Nemiña (2007,), que el país debería comenzar a cancelar con sus propios recursos los vencimientos de deuda con el organismo.

Tal como se demostró, el respaldo de Estados Unidos estuvo orientado por la necesidad de preservar sus intereses estratégicos. En tal sentido, una vez concluido de manera exitosa el canje de deuda en junio de 2005, eliminando los peligros de contagio y despejando las dudas respecto a la necesidad o no de colocar nuevos fondos para capear la tormenta financiera que había afectado a Argentina y amenazaba al resto de la región, las coincidencias y los intereses convergentes entre ambos actores se disiparon. A partir de entonces Argentina debía resolver las cuestiones pendientes del default sin la cuña política norteamericana.

\section{Conclusiones}

Durante el proceso de reestructuración de su deuda externa, Argentina logró preservar autonomía, pero esta fue algo engañosa y endeble debido a que -tal como se demostró-, el principal respaldo con el que contó resultó ser de naturaleza circunstancial. En tal sentido y retomando los interrogantes planteados en la introducción, queda claro que la autonomía alcanzada fue más bien el producto de un contexto particular y no el resultado de un proceso de construcción sostenible en el tiempo.

Estas afirmaciones no deben interpretarse como un argumento en contra de la búsqueda de mayores márgenes de maniobra en el plano internacional por parte de los Estados periféricos y en desarrollo, ni tampoco como una crítica a la manera en la cual Argentina manejó el problema del default, al menos durante el período bajo estudio en este trabajo. Por el contrario, con las ideas expuestas a lo largo del presente artículo se procuró llamar la atención acerca de la importancia y la necesidad de analizar las bases que hicieron posible el logro de autonomía para poder evaluar el grado real de sustentabilidad de la misma y de ese modo evitar la sobreestimación de sus alcances en el futuro -con todos los costos que esto implica-. En este punto radica el principal aporte del trabajo, tanto por sus implicancias teóricas en el marco de los debates sobre la autonomía, como por sus consecuencias prácticas en lo relativo a la relación de Argentina con el sistema financiero internacional.

En términos teóricos, cabe recordar que la construcción autonómica constituye siempre un proceso cíclico y rara vez lineal, el cual se caracteriza por tener avances y 
retrocesos, marchas y contramarchas. La clave radica justamente en comprender de manera correcta tales ciclos y en tal sentido, adecuar las decisiones internacionales al margen de maniobra potencial disponible en cada momento o situación. El error en este cálculo, ya sea por exceso o por defecto, es perjudicial para el objetivo autonomizante (Puig, 1984, pp. 72-73). Es aquí donde el análisis minucioso de la naturaleza del respaldo real con el que cuenta la autonomía constituye un elemento crucial. Tal como se destacó, la ampliación de los márgenes de decisión propia no puede ser tan solo una cuestión de voluntad, es preciso que exista algún tipo de poder que le brinde un soporte suficiente y garantice que las acciones implementadas podrán sostenerse y no acarrearán costos mayores posteriormente (Creus, 2011).

En términos prácticos, el estudio del período 2002 a 2005, momento en el cual Argentina sorprendió por el modo en el cual pudo lograr sus objetivos a pesar de la fuerte presión ejercida por parte de actores poderosos del sistema financiero internacional, resulta fundamental para entender el devenir posterior del proceso y las dificultades experimentadas para lograr su cierre definitivo. Luego del canje exitoso de 2005, Argentina pretendió seguir por la senda autonomista y resolver -de acuerdo con sus propios criterios- las cuestiones pendientes del default tales como la regularización de la deuda con el Club de París, la normalización de las relaciones con el FMI -afectadas por la resistencia del país a someterse a la revisión de su economía en función de lo dispuesto por el artículo IV del estatuto del organismo-, el arreglo de los juicios con sentencia que diferentes empresas habían llevado adelante contra el país en el marco del Centro Internacional para el Arreglo de Diferencias relativas a Inversiones (CIADI); y la resolución de la deuda con aquellos acreedores privados que no aceptaron la oferta argentina -holdouts-. Sin embargo, sin el respaldo de Estados Unidos, fundamental en la construcción autonómica durante la primera etapa, el resultado no sería el mismo, poniendo de manifiesto su fragilidad y los peligros de no acomodarse a las limitaciones del nuevo contexto.

La estructuración de un vínculo más equilibrado con el sistema financiero internacional -imprescindible para el logro de mayores márgenes de maniobra- requiere inevitablemente tomar en consideración los aspectos planteados.

\section{Referencias}

Bembi, M., \& Nemiña, P. (2007). Neoliberalismo y desendeudamiento. La relación Argentina-FMI. Buenos Aires: Capital Intelectual.

Busso, A. (2006). La persistencia de Kirchner y los vínculos con Estados Unidos: más ajustes que rupturas. En Bologna, A. (Comp.), La política exterior del gobierno de Kirchner (pp.11-127). Rosario: UNR Editora.

Cibils, A., Weisbrot, M., \& Kar, D. (2002). Argentina Since Default: The IMF and the Depression. Washington D.C.: Center for Economic and Policy Research. 
Cooper, A., \& Momani, B. (2005). Negotiating Out of Argentina's Financial Crisis: Segmenting the International Creditors. New Political Economy, 1O(3), 305-320.

Creus, N. (2011). La autonomía en la política exterior argentina frente a un desafío inexorable: reflexionar sobre el poder. En Miranda, R. (Comp.). Política exterior. Conceptos y enfoques en torno a Argentina (pp. 49-76). Rosario: Ediciones Pia.

Damill, M., \& Frenkel, R. (2013). La economía argentina bajo los Kirchner: una historia de dos lustros. Documentos Técnicos, Iniciativa para la Transparencia Financiera, 40.

Damill, M., Frenkel, R., \& Rapetti, M. (2005). La deuda argentina: Historia, default y reestructuración. Desarrollo Económico, 45(178), 187-233.

De la Balze, F. (1998). La política exterior de la reincorporación al primer mundo. En Cisneros, A. (Comp.). Política Exterior Argentina, 1989-1999. Historia de un éxito (pp.107-178). Buenos Aires: Grupo Editor Latinoamericano (GEL).

Eatwell, J. \& Taylor, L. (2006). Finanzas globales en riesgo. Un análisis a favor de la regulación internacional. Buenos Aires: Siglo XXI Editores.

Escudé, C. (1992). Realismo periférico. Fundamentos para la nueva política exterior argentina. Buenos Aires: Planeta.

Fernández Alonso, J. (2006). La reinserción financiera como eje rector de la agenda externa argentina post-default. En Bologna, A. (Comp.). La política exterior del gobierno de Néstor Kirchner (pp.31-88). Rosario: UNR Editora.

Ferrer, A. (2003a). Acerca del acuerdo de la Argentina con el Fondo Monetario Internacional de enero de 2003. Buenos Aires: Grupo Fénix.

Ferrer, A. (2003b). El acuerdo de Argentina con el FMI de septiembre de 2003. Buenos Aires: Grupo Fénix.

Helleiner, E. (2005). The Strange Story of Bush and the Argentine Debt Crisis. Third World Quarterly, 26(6), 951-969.

Lavagna, R. (2011). El desafío de la voluntad. Buenos Aires: Sudamericana.

Lane, T., \& Phillips S. (2000). Does IMF Financing Result in Moral Hazard?. IMF Working Paper, WP/oo/168. US: Policy Development and Review Department.

Mussa, M. (2002). Argentina y el FMI. Del triunfo a la tragedia. Buenos Aires: Planeta.

Puig, J. C. (1980). Doctrinas internacionales y autonomía latinoamericana. Caracas: Instituto de Altos Estudios de América Latina, Universidad Simón Bolívar. 
Puig, J. C. (1984). Introducción. En: Puig, J. C. (Comp.). América Latina: políticas exteriores comparadas, Tomo I (pp. 24-90). Buenos Aires: Grupo Editor Latinoamericano (GEL).

Rodrik, D. (2003). Argentina: A case of globalisation gone too far or not far enough?. En Teunissen, J., \& Akkerman, A. (Eds.). The Crisis That Was Not Prevented: Lessons for Argentina, the IMF and Globalization (pp. 15-21). The Hague: Forum on Debt and Development (FONDAD).

Stiglitz, J. (2002). Argentina's Lessons. Project Syndicate, January $8^{\text {th }}$. Recuperado de http://www.project-syndicate.org/commentary/argentina-s-lessons

Sturzenegger, F., \& Zettelmeyer, J. (2006). Debt Defaults and Lessons from a Decade of Crisis. Cambridge, Massachusetts: MIT Press.

Taylor, J. (2004/2002). Aumentar el crecimiento económico y la estabilidad en los mercados emergentes. En Artana, D. \& Dorn, J. (Comp.). Crisis Financieras Internacionales: ¿qué rol le corresponde al gobierno? (pp. 167-175). Buenos Aires: Cato Institute. 